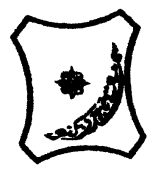

Bayero Journal of Pure and Applied Sciences, 12(1): 112 - 117

Received: March, 2019

Accepted: June, 2019

ISSN $2006-6996$

\title{
ASSESSMENT OF METAL AVAILABILITY IN DUMPSITE SOIL USING NEUTRON ACTIVATION ANALYSIS
}

\author{
${ }^{* 1}$ Mohammed, A., ${ }^{2}$ Umar, S., $^{2}$ Ismaila, A. and ${ }^{3}$ Abdulkarim, M. S. \\ ${ }^{1}$ Department of Physics, School of Science Education, Federal College of Education (Technical), Gusau- \\ Nigeria \\ ${ }^{2}$ Department of Physics, Faculty of Physical Sciences, Ahmadu Bello University, Zaria-Nigeria \\ ${ }^{3}$ Department of Applied Sciences, College of Science and Technology Kaduna Polytechnic, Kaduna-Nigeria \\ *Corresponding Author's Email: ahmedmohammed7984@gmail.com
}

\begin{abstract}
Contamination from municipal waste can increase the natural levels of heavy metals in soil, creating a health hazard to public and the environment. Environmental samples from the residential dumpsite were analyzed to determine the content and concentrations of various elements in six soil plumes taken at different depths: 0, 25, 50, 100, 120 and $150 \mathrm{~cm}$ respectively from the top layer down the soil profiles. The instrumental neutron activation analysis (INAA) technique was employed in the study. The analysis results revealed twenty nine elements comprising of heavy metals, reference and radioactive elements. Further analysis indicates a fluctuation in concentration of the elements down the profile and predicted elements exhibits a strong positive correlation amongst themselves. The decrease in concentrations of some elements in the middle of the sample follows the order $\mathrm{Mg}<\mathrm{Na}<\mathrm{Fe}<\mathrm{K}<\mathrm{Al}$. The results show that despite slow absorption reaction of the metal within the middle of the sample, these metals displayed a uniform distribution within the specific soil matrix.
\end{abstract}

Key words:Element, infiltration, neutron analysis, soil texture and degraded dumpsite

\section{INTRODUCTION}

Soil infiltration refers to the soils ability to allow leachate move downward by force of gravity through seepage into and through the soil profiles (Farzad et al., 2015). Infiltration study is important when estimates of groundwater and soils pollution are necessary. The infiltration rate is determined by the interaction of a number of physical, chemical and soil characteristics or properties.In the infiltration process, leachate penetrates the soil surface due to the combined influence of gravity and capillary forces. Both forces act in the vertical direction to cause percolation downward. Capillary forces also act to divert leachate laterally from larger pores to capillary pore spaces which are much smaller in dimension, but may be very numerous (Farzad, et al., 2015).

Leachate percolation through the soil is governed by Darcy's law, which states that the flux is equal to the product of the hydraulic conductivity and the hydraulic gradient (Farzad, et al., 2015). The hydraulic gradient is comprised of the gravity, pressure, osmotic and matric (movement of leachate from wet or full pores to dry soil) potentials (Singer and Munns, 2005). The hydraulic conductivity of soil is strongly influenced by the soil texture, that is, the relative proportions of sand, silt and clay. Clay particles are particularly important as their small size makes them able to fill the voids between larger particles while their charge orientation gives them a crucial role in binding the soil matrix into larger structures.

Childs et al. (1993) noted that, regions of lighter texture or sandy soil within a field often have higher intake rates. However, Van et al. (1991) found a positive correlation between the clay content and the initial infiltration rate while the silt content was negatively correlated.

Soil water content also has a direct impact on the degree of soil cracking which in turn has a large impact on the infiltration function (Mailhol and Gonzalez, 1993). 
BAJOPAS Volume 12 Number 1, June, 2019

Cracking occurs within many clay soils. Cracks serve as pathways through which water can quickly enter the soil. Qian et al. (1996) reported that the influence of soil texture on metal solubility in soils is best expressed in terms of the soils division into clay, silt and sand fractions; this has prompted the use of instrumental neutron activation techniques to analyze the content and concentration of elements present in the soil samples.

Heavy metals are significant environmental pollutants and their toxicity is a problem of increasing significance for nutritional, ecological, evolutionary and environmental reasons (Jaishankar et al., 2014). The toxicity of heavy metals is affected by factors such as soil texture, organic matter, and $\mathrm{pH}$ and their health hazards depends on the exposure time and amount, i.e. the food consumed over time and volume of contaminated soil (Grubinger and Ross, 2011).

The aim of this study is to investigate the influence of the soil types on movement of elements and to determine the elemental contents, concentration and vertical distribution in the soil profiles. Statistical analysis was employed in determining the correlation and clustering on elements content.

\section{Theory}

Neutron Activation Analysis (NAA) was discovered in 1936 when Hevsy and Levi found that samples containing certain earth elements become highly radioactive after exposure to a source of neutrons. This analytical technique is powerful in identifying many elements present in samples of unknown composition performing both quantitative and qualitative multi-element analysis of major, minor and trace elements in samples (Chaubey et al., 2011).

An isotope of atomic mass $A$ and atomic number $Z$ when placed in a neutron flux will, in general, absorb a neutron to become the isotope $(A+1, Z)$. Some resulting isotopes, being unstable, will decay, emitting one or more gamma-rays with energies and half-life characteristic of the particular isotope. During irradiation, the naturally occurring stable isotopes of most elements that constitute alluvial samples are transformed into radioactive isotope by neutron capture. The number of radionuclide produced in activation of a natural isotope is given by the expression:

$$
N_{(A+1)}=\frac{\emptyset \sigma_{a A} N_{O A}}{\lambda_{(A+1)}}\left(1-e^{-\lambda(A+1) T}\right) e^{\lambda(A+1) l}
$$

(1)
The activity, $\mathrm{A}$ is given by:

$$
A=\frac{d N_{(A+1)}}{d t}
$$

where $\phi$ and $\sigma_{a A}$ in Equation (1) are the neutron flux and the neutron absorption cross-section of the original isotope, $N_{O A}$ is the number of nuclei of element under consideration of isotope $A, \lambda(A+1)$ is the decay constant of the created isotope, $T$ is the irradiation time. The parameter $d t$ in Equation (2) is the time between stop of the activity and start of the counting process.

The basic essentials required to carry out an analysis of soil samples by NAA are source of neutrons, higher purity germanium (HPGE) detector coupled with multi-channel analyser (MCA) and a printer (Chaubey, et al., 2011).

The flow of a liquid through a porous media is govern by Darcy's law given by Equation (3).

$Q=-K A \frac{d h}{d l}$

(3)where $A$ is the cross-sectional area through which flow can occur, $\frac{d h}{d l}$ is hydraulic gradient and $\mathrm{K}$ is a constant. The negative sign indicates that water flowing from highest to lowest hydraulic head.

\section{MATERIALS AND METHOD}

3.1. Site description: College road dumpsite is located within the extreme eastern part of the Sardauna Memorial College at Unguwan Dosa in Kaduna metropolis Nigeria. It is situated within a residential houses and has been in used by the residents of Unguwan Dosa and its neighboring areas for over three decades. It covered a land area of about $250 \mathrm{~m} \times 400 \mathrm{~m}$.

\subsection{Sample collection:}

A pit was dug within the polluted dumpsite to reveal its profiles. With the help of hoe, digger and parker, soil plume were collected at different depths: 0, 25, 50, 100, 120 and $150 \mathrm{~cm}$ respectively. The collected soil samples were emptied into polyethylene bags, which were earlier cleaned using nitric acid, pure water and acetone. Samples were tied in a bags and labeled according to their respective depths to prevent interference or mix up of soil samples. The soil samples were double bagged to reduce chances of cross contamination. 
BAJOPAS Volume 12 Number 1, June, 2019

\subsection{Sample analysis:}

Samples were first dried through an open air in a room and then dried in an oven for some days at a temperature of $60^{\circ} \mathrm{C}$. They were then crushed into fine powders of microns size particles in an agate mortar to make them homogeneous. About $0.15 \mathrm{mg}$ of each sample were put in a polyethylene bags labeled B1, B2, B3, B4, B5 and B6. The bags together with vials were washed in distilled water three times and taken for analysis at Center for Energy Research and Training (CERT), Ahmadu Bello University Zaria, Nigeria. For long irradiation, samples and standards were packed together in an irradiation vials and irradiated simultaneously for six hours with a research reactor operated at $15 \mathrm{~kW}$ and at a thermal neutron flux of $5 \times 10^{11}$ neutrons per second. The concentration of the irradiated samples and standards were measured and their results are presented in section 3.

\section{RESULTS AND DISCUSSIONS}

4.1 Analysis of vertical distribution and total concentrations of elements in soil profiles

The depth wise studies of soil plume across the profiles present a total of twenty nine elements displayed in Table 1 . These elements are evenly distributed in each of the soil plumes and their concentrations fluctuated in the soil profiles within the specified depth. The detection and distributions of these elements in each of the soil plume down the profiles are evidence of leaching process in the dumpsite. The leaching might have been enhanced by the nature of the soil structure as it is varies in composition and types as reported (Abdullahi, 2009; Ahmed et al., 2017; Jiao et al., 2015). Similarly, Kirpichtchikova et al. (2006) and Li et al. (2013) reported that soils are the major sink for elements released into the environment. Furthermore, Adriano (2003) observed that their total concentration in soils persists for a long time after their introduction. Meanwhile the report of (McLean and Bledsoe, 2002) noted that metal-soil interaction is such that when metals are introduced at the soil surface, downward transportation does not occur to any great extent unless the metal retention capacity of the soil is over loaded and metal interaction with the associated waste matrix enhances mobility. In contrast, Matini et al. (2011) noted that, metal displayed a systematic drop in concentration with depth. $\mathrm{Na}$ is the only element detected in the soil samples showing increase concentration with depth.

The analysis of results in Table 1 shows that the metals $\mathrm{Al}$ and $\mathrm{Fe}$ have the highest mean value concentration of $64517 \mathrm{ppm}$ and $29346.7 \mathrm{ppm}$ while $\mathrm{Lu}$ and $\mathrm{Ba}$ indicate the lowest mean values of $0.47 \mathrm{ppm}$ and $0.12 \mathrm{ppm}$ respectively. The higher concentration of both $\mathrm{Al}$ and $\mathrm{Fe}$ in all the samples may not be unconnected to the nature of the dump/refuse deposited and decomposed over a period of time on this site. A large quantity of scrap items made up of $\mathrm{Fe}$ and $\mathrm{Al}$ have been dumped over long period and therefore constitutes the major hazard to this environment as clearly shown in the table. The authors are also in the opinion that the concentration of these elements may be connected to their ionic mobility/solubility when come in contact with rain water and other liquid influents. Heavy metal toxicity has proven to be a major threat and have many several health risks which last for a long period of time. They sometimes act as a pseudo element of the body while at certain times they may even interfere with metabolic processes thereby affecting the normal functioning of the human body (Jaishankar, et al., 2014). It has been reported that too much exposure to aluminum dust may increase the risk of cardiovascular disease and dementia of the Alzheimer's type (Daniel Krewski et al., 2009; Peters et al., 2013).It can also lead to various disorders induced by free radical formation. The toxicity of iron on cells has led to iron mediated tissue damage involving cellular oxidizing and reducing mechanisms and their toxicity towards intracellular organelles such as mitochondria and lysosomes (Jaishankar, et al., 2014). 
BAJOPAS Volume 12 Number 1, June, 2019

Table 1: Analytical results of INAA of six geological samples I in site B

\begin{tabular}{|c|c|c|c|c|c|c|c|}
\hline \multirow[b]{2}{*}{ Elements } & \multicolumn{7}{|c|}{ Concentration (ppm) } \\
\hline & B1 & B2 & B3 & B4 & B5 & B6 & Mean \\
\hline $\mathrm{Mg}$ & BDL & BDL & 2210 & 3668 & 3437 & 5036 & 3588 \\
\hline $\mathrm{Al}$ & 32860 & 26580 & 62600 & 74740 & 95050 & 95270 & 64517 \\
\hline $\mathrm{Ca}$ & 4847 & 2548 & $\mathrm{BDL}$ & 2456 & 2945 & 6482 & 3856 \\
\hline $\mathrm{Ti}$ & 2419 & BDL & 2061 & 3400 & BDL & 3065 & 2736.3 \\
\hline V & 44.2 & 56 & 59 & 46 & 29 & 44 & 46.4 \\
\hline $\mathrm{Mn}$ & 327 & 233 & 99 & 144 & 150 & 190 & 190.5 \\
\hline Dy & 4.5 & 4.6 & 5.6 & 5.1 & 6.0 & 3.5 & 4.88 \\
\hline $\mathrm{Na}$ & 2275 & 2364 & 3669 & 5701 & 9089 & 15850 & 649 \\
\hline $\mathrm{K}$ & 1452 & 24260 & 40830 & 30780 & 33410 & 24010 & 25790 \\
\hline As & 2.7 & 4.6 & 1.5 & 1.6 & BDL & BDL & 2.6 \\
\hline $\mathrm{Br}$ & 2.3 & 2.7 & 2.3 & 2.9 & BDL & BDL & 2.55 \\
\hline La & 109.8 & 45.9 & 52.6 & 39.3 & 70.3 & 56.2 & 62.35 \\
\hline Sm & 16.5 & 5.65 & 6.94 & 5.48 & 10.89 & 7.27 & 7.27 \\
\hline U & 8.6 & 6.2 & 5.3 & 4.7 & 8.7 & 4.01 & 6.25 \\
\hline Sc & 4.42 & 5.02 & 4.95 & 6.4 & 3.96 & 4.9 & 4.94 \\
\hline $\mathrm{Cr}$ & 56 & 103 & 41 & 73.3 & 19.7 & 39.2 & 55.4 \\
\hline $\mathrm{Fe}$ & 31240 & 58680 & 27990 & 24010 & 16070 & 18090 & 29346.7 \\
\hline Co & 6.04 & 8.02 & 9.4 & 10.5 & 12.9 & 6.5 & 8.89 \\
\hline $\mathrm{Zn}$ & 291 & 122 & 42 & 40.1 & 35.1 & 43.5 & 95.6 \\
\hline $\mathrm{Rb}$ & 90 & 1446 & 211 & 201.7 & 194 & 168.4 & 385.2 \\
\hline $\mathrm{Sb}$ & BDL & 1.5 & 0.49 & BDL & BDL & 0.7 & 0.90 \\
\hline Cs & 3.2 & 4.0 & 5.2 & 8.6 & 6.5 & 5.9 & 0.12 \\
\hline $\mathrm{Ba}$ & 499 & 638 & 1022 & 788 & 898 & 642 & 747.8 \\
\hline Eu & 1.34 & 1.0 & 1.3 & 1.1 & 1.1 & 1.3 & 1.19 \\
\hline $\mathrm{Yb}$ & 3.1 & 2.2 & 2.0 & 2.3 & 7.9 & 2.3 & 3.3 \\
\hline Lu & 0.59 & 0.42 & 0.4 & 0.3 & 0.85 & 0.23 & 0.47 \\
\hline $\mathrm{Hf}$ & 12.3 & 14.5 & 12.4 & 10.00 & 5.01 & 4.4 & 9.77 \\
\hline Ta & 1.07 & 1.1 & 1.4 & 2.1 & 1.46 & 1.4 & 1.42 \\
\hline Th & 51.8 & 22.3 & 25.0 & 10.3 & 22.5 & 7.0 & 23.15 \\
\hline
\end{tabular}

BDL: Below Detection Limit 
BAJOPAS Volume 12 Number 1, June, 2019

4.2 Statistical analysis

Table 2:Pearson correlation analysis of total elements concentrations between soil profiles

\begin{tabular}{lllllll} 
Sample & B1 & B2 & B3 & B4 & B5 & B6 \\
\hline B1 & 1 & $0.862^{* *}$ & $0.801^{* *}$ & $0.830^{* *}$ & $0.769^{* *}$ & $0.799^{* *}$ \\
B2 & $0.862^{* *}$ & 1 & $0.756^{* *}$ & $0.681^{* *}$ & $0.569^{* *}$ & $0.561^{* *}$ \\
B3 & $0.081^{* *}$ & $0.756^{* *}$ & 1 & $0.979^{* *}$ & $0.948^{* *}$ & $0.919^{* *}$ \\
B4 & $0.083^{* *}$ & $0.681^{* *}$ & $0.979^{* *}$ & 1 & $0.989^{* *}$ & $0.978^{* *}$ \\
B5 & $0.769^{* *}$ & $0.569^{* *}$ & $0.948^{* *}$ & $0.989^{* *}$ & 1 & $0.992^{* *}$ \\
B6 & $0.799^{* *}$ & $0.561^{* *}$ & $0.919^{* *}$ & $0.978^{* *}$ & $0.992^{* *}$ & 1 \\
\hline
\end{tabular}

$* *$ Correlation is significant at 0.01 level (2-tailed)

Table 3:Pair samples correlation analysis

\begin{tabular}{lllll}
\hline & & N & Correlation & Significance \\
\hline Pair 1 & B1 \& B2 & 27 & 0.862 & 0.000 \\
Pair 2 & B3 \& B4 & 29 & 0.979 & 0.000 \\
Pair 3 & B5 \& B6 & 29 & 0.992 & 0.000 \\
\hline
\end{tabular}

Table 4:Friedman test for mean rank

\begin{tabular}{lllllll}
\hline Soil profile & B1 & B2 & B3 & B4 & B5 & B6 \\
\hline Mean rank & 3.52 & 3.54 & 3.61 & 3.59 & 3.72 & 3.02 \\
\hline
\end{tabular}

\subsubsection{Clustering analysis}

In the middle of samples B3, B4, B5 and B6, the concentration of five elements decreases in the order of $\mathrm{Mg}<\mathrm{Na}<\mathrm{Fe}<\mathrm{K}<\mathrm{Al}$ with slight exception in $\mathrm{B} 6$, where Ca replaces $\mathrm{Mg}$. Lu was detected as the element with least concentration and $\mathrm{Al}$ as the element with highest concentration in all the entire soil samples with exception of B2. Statistics indicates $55.2 \%$ of all the elements detected in the samples shows increase concentration from top surface to B2 while $44.8 \%$ of these elements indicates raise in concentration from B2 to B3. This increase is due to acidic nature of the top surface as reported by Matini, et al. (2011) that acidic soil induces heavy metals dissolution, raises the soil $\mathrm{PH}$ and enhance leaching process.

The elements and their concentrations encloses in the brackets such as $\mathrm{Mg}$ (B1, B2, Ca (B3), Ti (B2, $\mathrm{B} 5)$, As and $\mathrm{Br}(\mathrm{B} 5, \mathrm{~B} 6)$ and $\mathrm{Sb}(\mathrm{B} 1, \mathrm{~B} 4, \mathrm{~B} 5)$ fell below detection limit.

\subsubsection{Pearson correlation analysis of} elements concentrations in each soil profiles Table 2 summarizes correlations statistics of twenty nine elements detected from six soil samples with each other. Analysis of the results clearly indicates a strong positive correlation amongst the elements from different soil samples. The relationship indicates common anthropogenic source of the elements which shows that they are not affected by the chemical change.

The results of pair sample correlation analyses between elements from adjacent soil samples is presented in Table 3. This statistical data is aimed to elucidate if the different soil samples from which elements are obtained are of same soil texture. The result indicates no significant difference in elements from each of the adjacent soil samples and by implication, the soil samples are from single class.

In Table 4, the mean ranking shows high accumulations of the elements down the profiles with increasing order of accumulation in the order of $\mathrm{B} 5>\mathrm{B} 3>\mathrm{B} 4>\mathrm{B} 2>\mathrm{B} 1>\mathrm{B} 6$. It means metal accumulation down the profiles varies with adhesion property of soil type and greater in the order shown.

\section{CONCLUSION}

The analysis of soil plume using instrumental neutron activation analysis revealed a total of twenty nine elements evenly distributed down the profiles. The concentrations of these elements fluctuated from top soil down the profiles with the Al showing the highest concentration in all the soil samples and Lu shows the least concentration. The Pearson statistical analysis indicates strong positive correlations amongst elements. The mean ranking indicates higher accumulations of the elements down the profiles. There are almost no definite trends in all the entire samples. The cluster analyses of some group of elements across the entire samples show common behavior. It is recommended that further research should be conducted with a soil plumes taken at a relatively higher depth above $150 \mathrm{~cm}$ in order to understand the extent of seepage of elements in soil matrix. 
BAJOPAS Volume 12 Number 1, June, 2019

\section{Acknowledgement}

The authors would like to thank the management of Centre for Energy Research and Training (CERT), Zaria for the sample analysis with their reactor facility. We would like to convey a special thanks to Mr. Shehu Usman Shika and his colleagues in reactor department, CERT, Zaria for their helpful advice and suggestions. The financial

\section{REFERENCES}

Abdullahi, K. N. (2009). Unpublished PhD Thesis. Ahmadu Bello University, Zaria-Nigeria.

Adriano, D. C. (2003). Trace elements in the terrestrial environment. Springer Verlag, New York.

Ahmed, M. S., Tanko, A. I., Eduvie, M. O. and Ahmed, M. (2017). Assessment of Groundwater Vulnerability in Kaduna Metropolis, Northwest Nigeria. Journal of Geoscience and Environment Protection. 5(06), 99.

Chaubey, A. K., Taddesse, A., Assefa, D. and Hibstie, A. Y. (2011). Elemental Analysis of Alluvial Soil Samples Using Neutron Activation Techniques in Blue Nile Basin, East Gojjam, Ethiopia. E-International Scientific Research Journal. III(4), 232-242.

Childs, J., Wallender, W. and Hopmans, J. (1993). Spatial and seasonal variation of furrow infiltration. Journal of irrigation and drainage engineering. 119(1), 74-90.

Daniel Krewski, Robert A Yokel, Evert Nieboer, David Borchelt, Joshua Cohen, Jean Harry, Sam Kacew, Joan Lindsay, Amal M Mahfouz and Rondeau, V. (2009). Human Health Risk Assessment for Aluminium, Aluminium Oxide, and Aluminium Hydroxide. $J$ Toxicol Environ Health B Crit 10(Suppl 1), 1-269.

Farzad, H., Hassan, S. and Mehdi, F. (2015). Factors affecting the infiltration of agricultural soils: review International Journal of Agronomy and Agricultural Research (IJAAR). 6(5), 21-35.

Grubinger, V. and Ross, D. (2011). Interpreting the Results of Soil Tests for Heavy Metals. University of Vermont Extension.

Jaishankar, M., Tseten, T., Anbalagan, N., Mathew, B. B. and Beeregowda, K. N. ( 2014). Toxicity, mechanism and health effects of some heavy metals. Interdiscip Toxicol. 7(2), 60-72.

Jiao, X., Teng, Y., Zhan, Y., Wu, J. and Lin, X. (2015). Soil heavy metal pollution and risk support to Mr. Ahmed Mohammed by the Federal College of Education (Technical), Gusau through the TETFund intervention scheme is greatly acknowledged.

\section{Conflict of Interest}

The authors declared no conflict of interest regarding the publication of this article.

assessment in Shenyang industrial district, Northeast China. PloS one. 10(5), e0127736.

Kirpichtchikova, T. A., Manceau, A., Spadini, L., Panfili, F., Marcus, M. A. and Jacquet, T. (2006). Speciation and solubility of heavy metals in contaminated soil using X-ray microfluorescence, EXAFS spectroscopy, chemical extraction, and thermodynamic modeling. Geochimica et Cosmochimica Acta. 70(9), 2163-2190.

Li, X., Liu, L., Wang, Y., Luo, G., Chen, X., Yang, X., Hall, M. H., Guo, R., Wang, H. and Cui, J. (2013). Heavy metal contamination of urban soil in an old industrial city (Shenyang) in Northeast China. Geoderma. 192, 50-58.

Mailhol, J.-C. and Gonzalez, J.-M. (1993). Furrow irrigation model for real-time applications on cracking soils. Journal of irrigation and drainage engineering. 119(5), 768-783.

Matini, L., Ongoka, P. R. and Tathy, J. P. (2011). Heavy metals in soil on spoil heap of an abandoned lead ore treatment plant, SE Congo-Brazzaville. African journal of environmental science and technology. 5(2), 89-97.

McLean, J. and Bledsoe, B. (2002). Behavior of Metals In Soils. United States of America: United States Environmental Protection Agency, Washington, D.C.

Peters, S., Reid, A., Fritschi, L., Klerk, d. N. and Musk, A. (2013). Long-term effects of aluminium dust inhalation. Occup Environ Med. 70(12), 864-868.

Qian, J., Shan, X.-q., Wang, Z.-j. and Tu, Q. (1996). Distribution and plant availability of heavy metals in different particle-size fractions of soil. Science of the Total Environment. 187(2), 131-141.

Singer, M. J. and Munns, D. N. (2005). Soils: An Introduction.

Van, H., Cassel, D. and Daniels, R. (1991). Infiltration variability and correlations with surface soil properties for an eroded Hapludult. Soil Science Society of America Journal. 55(2), 486-492. 